\title{
Physicians' knowledge of the Glasgow Coma Scale in a Nigerian university hospital: is the simple GCS still too complex?
}

\author{
Amos O. Adeleye ${ }^{1 *}$, Mayowa O. Owolabi ${ }^{2}$, Taopheeq B. Rabiu ${ }^{3}$ and Adebola E. Orimadegun ${ }^{4}$ \\ 1 Division of Neurological Surgery, Department of Surgery, College Of Medicine, University of Ibadan, Ibadan, Nigeria \\ ${ }^{2}$ Neurology Unit, Department of Medicine, College of Medicine, University of Ibadan, Ibadan, Nigeria \\ ${ }^{3}$ Department of Neurological Surgery, University College Hospital, Ibadan, Nigeria \\ ${ }^{4}$ Institute of Child Health, College of Medicine, University of Ibadan, Ibadan, Nigeria
}

\section{Edited by:}

Gregory Gruener, Loyola University, USA

\section{Reviewed by:}

Gregory Gruener, Loyola University, USA

Kevin N. Sheth, University of Maryland School of Medicine, USA

*Correspondence:

Amos O. Adeleye, Lecturer and Consultant Neurological Surgeon, Department of Neurological Surgery, University College Hospital, PMB 5116, Ibadan 200001, Nigeria. e-mail: femdoy@yahoo.com

\begin{abstract}
Objective: The Glasgow Coma Scale, GCS, is a universal clinical means of quantifying the level of impaired consciousness. Although physicians usually receive undergraduate and postgraduate training in the use of this scale in our university hospital we are aware of studies suggesting that the working knowledge of the GCS among practising physicians might not be adequate. Methods: We carried out a questionnaire-based survey across all specialties and levels of training of physicians in active patient care in a Nigerian university hospital. Results: Of the 100 physicians sampled, 98 correctly spelled out what the three-letter abbreviation, GCS, stands for. Ninety-three percent also conceded it to be an important clinical rating scale. However, only 55-89\% of the participants correctly identified the three respective clinical variables, (eye opening, verbal response, and motor response), of the GCS. More particularly, the participants' ability to itemize and correctly score all the respective components of each of the three clinical variables ranged from 0 to $35 \%$ across specialties and levels of training. Performance was best for the four-item eye opening variable and, worst for the six-item motor response variable. Conclusion: In our university hospital, practising physicians' working knowledge of the GCS is inadequate and is dependent on the degree of the complexity of each of the three clinical variables of the scale.
\end{abstract}

Keywords: Glasgow coma scale, physicians' knowledge, Nigeria

\section{INTRODUCTION}

The introduction of the Glasgow Coma Scale (GCS) in 1974 and initially to access consciousness after head trauma was recognized as an advancement in the clinical assessment and quantification of unconsciousness (Teasdale and Jennett, 1974; Peters, 2010). Unlike the prior highly subjective ways of describing states of impaired consciousness, here was a well elucidated, objective, and reproducible grading scale of consciousness and its varying perturbations. The GCS was not only felt to be clinically useful, but was acclaimed to be very simple to learn. Physicians and nurses in the Glasgow Neurological Institute, where the scale evolved also demonstrated the reliability of the scale by the concordance of interrater scores. (Jennett et al., 1976; Teasdale and Jennett, 1976, 1978).

It is no wonder that the global reception of the scale was immediate and, with only a few latter day exceptions, total (Teasdale and Jennett, 1978). Showing no language barrier, it soon became the most universally utilized level of consciousness scale worldwide; made redundant some earlier, even simpler scales; and even more authoritatively became incorporated into many trauma and critical illness clinical classification systems, and some trauma outcome prediction models (Teasdale et al., 1978; Zuercher et al., 2009).
Despite its "global" reach, there remained some doubts concerning its acclaimed strengths of adequacy, flexibility for varying clinical scenarios, inter-rater reliability, and simplicity as demonstrated by a physicians' working knowledge of the scale (Tesseris et al., 1991; Riechers et al., 2005). The last concern, physicians' knowledge of the GCS, is of particular interest to us in that our medical institution, the University College Hospital, Ibadan, is the foremost center of clinical and academic neuroscience education in Nigeria. It is actually not improbable that it holds the same preeminent position in the sub-Saharan Africa.

We carried out this prospective anonymous survey to assess the level of physicians' knowledge of the GCS in our university hospital. We also explored the determinants of this state of knowledge among the survey participants.

\section{MATERIALS AND METHODS}

This was a prospective survey using a self-administered semistructured questionnaire modified from that of Riechers et al., 2005 (Appendix 1). The questionnaire was in the English language which is our institution's formal language of education/communication. The information sought included (1) participants' levels of training, length of time from medical school graduation, and of practice including additional postgraduate training 
(2) participants' level of contact with emergency/resuscitation care including frequency and duration of their last practice in an emergency room, and their last contact with patients with altered level of consciousness and (3) the participants' working knowledge of the GCS. They were asked to identify the definition of the three-letter abbreviation, GCS, specific title of each of the three clinical variables and finally the scoring of the components of each variable.

The questionnaires were administered to the participants during hospital/departmental group meetings. Participation was entirely voluntary and anonymous. Participants were physicians at all levels of training and specialties. They had no prior notice of the study and did not have the chance to consult any reference material whilst completing the survey. After achieving a convenient sample of respondents, the questionnaires were each scored. For the title of GCS and of its clinical variables (i.e., eye opening, verbal response, and motor response), each response was scored in a yes/no pattern, whereas for the components of each clinical variable, the responses were scored based on the correct identification of the respective numbered components. This totaled an " 18 -item" scale with each of the three specific clinical variables having a maximum score of 6 , but not all using the complete range: (a) eye opening $0-4$, (b) verbal response $0-5$, and (c) motor response $0-6$. The participants were expected to identify, and so indicate in their scoring, which of the GCS clinical variables did not have up to six components (Figure 1).

\section{STATISTICAL ANALYSIS}

Data were analyzed using SPSS for Windows 15.0 (SPSS Inc., Chicago, IL, USA). Baseline data are presented in sizes and proportions (means and percentages) and in tabular forms as appropriate. The validity of recorded differences was tested with the KruskalWallis test for continuous non-parametric variables, whilst other tests of association were performed with the chi squared (or Fishers' exact) test for categorical variables. The level of statistical significance was pre-set at $p \leq 0.05$.

\section{RESULTS}

Responses from 100 participants were collated and analyzed. Table 1 shows some of their characteristics: $67 \%$ were resident

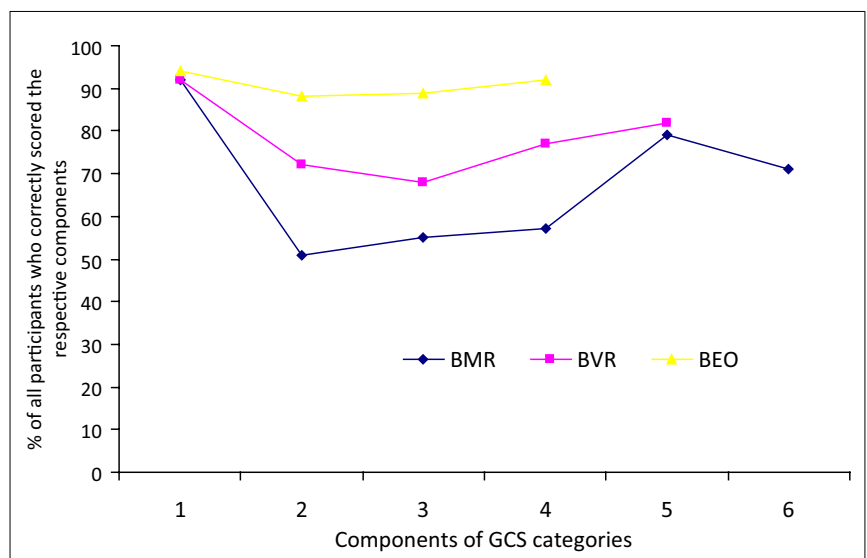

FIGURE 1 | Proportions of correct identification of the components of each clinical variable of the GCS by all the study participants. doctors and the participants were represented by multiple medical or surgical specialties. About $80 \%$ had contact with unconscious patients where the scale would be applicable; $77 \%$ had been on duty in the emergency department within a month of the survey. There were $90 \%$ who had received formal training in the use of the GCS, and $93 \%$ conceded that it is an important rating scale.

Almost all the participants, 98\%, correctly defined "GCS" as Glasgow coma scale. However, their performance declined while trying to identify the clinical variables of the GCS: About $89 \%$ correctly identified the eye opening variable (best eye opening, $\mathrm{BEO}$ ); $80 \%$ the verbal response variable (best verbal response, BVR), and $61 \%$ the motor response (best motor response, BMR). Only 55\% of the participants correctly identified all the clinical variables of the GCS, and physicians in the surgical and allied specialties performed significantly better $(p \leq 0.027)$ than their non-surgical counterparts in this aspect of the study. The former group of physicians also performed significantly better $(p \leq 0.008)$ than the latter in the rate of correctly identifying the BMR variable of the GCS, Table 2.

The participants' performance deteriorated when outlining and scoring the specific components of each of the three clinical variables of the GCS. The percentage of the participants by specialties who gave the correct scores for all the categories ranged from $0 \%$ among those in family medicine, pediatrics, and obstetrics and gynecology to $23.8 \%$ among those in internal medicine, $24 \%$ in surgery, and $35 \%$ in interns. There was no significant difference in this level of performance across the specialties, but may reflect inadequate samples. A similar explanation may explain why duration of medical practice and duration of the last clinical activity in the emergency room also did not appear to significantly affect study physicians' performance in this aspect of the survey, Table 3.

There were significant differences $(p \leq 0.05)$ across the specialties in the mean scores obtained for the scoring rubric of each of the three clinical variables (BEO, BVR, BMR) of the

Table 1 | Physicians' knowledge of the GCS in Nigeria's foremost university hospital: distribution of study participants.

\begin{tabular}{ll}
\hline Level of training & Number \\
\hline Intern or medical officer & 28 \\
Resident doctor & 68 \\
Consultant staff & 04 \\
SPECIALTY & \\
Internal medicine & 21 \\
Surgery & 13 \\
Anesthesia & 10 \\
Emergency room doctors & 11 \\
Ear, nose, throat & 07 \\
Obstet and Gynae & 04 \\
Pediatrics & 06 \\
House officers & 17 \\
Others* & 11 \\
\hline
\end{tabular}

*Others: ophthalmology, community medicine, family medicine. 
Table 2 | Comparison between surgical and non-surgical specialties of the participants who correctly identified the clinical variables of GCS.

\begin{tabular}{|c|c|c|c|c|c|c|c|}
\hline & \multicolumn{4}{|c|}{ Specialty } & \multicolumn{2}{|c|}{ Total (98)* } & \multirow[t]{2}{*}{$p^{* *}$} \\
\hline & \multicolumn{2}{|c|}{ Non-surgical (48) } & \multicolumn{2}{|c|}{ Surgical (50) } & $n$ & $\%$ & \\
\hline All GCS clinical variables identified & 21 & 43.8 & 33 & 66.0 & 54 & 55.1 & 0.027 \\
\hline BMR variable & 23 & 47.9 & 37 & 74.0 & 60 & 61.2 & 0.008 \\
\hline
\end{tabular}

${ }^{*}$ some participants had blank entries.

** chi squared test.

Table 3 | Participants who gave correct scores to the components of the clinical variables of the GCS (by duration of clinical practice and the last duty in the Accident and Emergency room).

\begin{tabular}{|c|c|c|c|c|c|c|c|c|}
\hline & \multicolumn{2}{|c|}{ BMR } & \multicolumn{2}{|c|}{ BVR } & \multicolumn{2}{|c|}{ BEO } & \multicolumn{2}{|c|}{ All categories } \\
\hline & $n$ & $\%$ & $n$ & $\%$ & $n$ & $\%$ & $n$ & $\%$ \\
\hline Less than 1 year $(22)$ & 7 & 31.8 & 12 & 54.5 & 19 & 86.4 & 6 & 27.3 \\
\hline $1-6$ years $(38)$ & 12 & 31.6 & 28 & 73.7 & 32 & 84.4 & 10 & 26.3 \\
\hline$>6$ years $(40)$ & 11 & 27.5 & 21 & 52.5 & 86 & 86.0 & 6 & 15.0 \\
\hline \multicolumn{9}{|c|}{ DURATION OFTHE LAST DUTY IN A AND E* } \\
\hline$\leq 1$ month and below (77) & 25 & 32.5 & 50 & 64.9 & 68 & 88.3 & 19 & 24.7 \\
\hline$>1$ month $(23)$ & 5 & 21.7 & 11 & 47.8 & 18 & 78.3 & 3 & 13.0 \\
\hline$p^{*}$ Value & \multicolumn{2}{|c|}{0.325} & \multicolumn{2}{|c|}{0.140} & \multicolumn{2}{|c|}{0.233} & \multicolumn{2}{|c|}{0.381} \\
\hline
\end{tabular}

Numbers in parentheses represent the numbers in each variable of the table as shown.

${ }^{*}$ Chi squared test.

GCS, Table 4. And as shown more dramatically in Figure 2, the longer the components of each clinical variable of the GCS, the worse the participants performed in defining the categories. Performance was the best for the BEO variable which has only four components and the worst for BMR with six components.

\section{DISCUSSION}

In this prospective questionnaire-based survey of 100 physicians in a Nigerian university hospital with a strong clinical and academic neuroscience practice, practising physicians' knowledge of the GCS is less optimal than what may be presumed. Only a little more than half, $55 \%$, of the physicians surveyed were able to correctly itemize the three clinical variables (eye opening, verbal response, and motor response) constituting the GCS. A smaller proportion were able to correctly score all the categories.

Yet, at least $90 \%$ of the respondents received formal training in the use of the scale, $93 \%$ consider the scale to be an important clinical tool, and $98 \%$ were able to define the abbreviation GCS. Finally, at least $80 \%$ of the respondents either frequently came into contact with unconscious patients or had been involved in emergency room patient care within a month prior to the survey.
Table 4 | Comparison of mean scores in each clinical variable of GCS by specialty.

\begin{tabular}{llll} 
All participants & $\begin{array}{l}\text { Mean for BMR } \\
\mathbf{4 . 0 5} \pm \mathbf{1 . 8 7} \\
\text { (out of } \mathbf{6} \text { ) }\end{array}$ & $\begin{array}{l}\text { Mean for BVR } \\
\mathbf{3 . 9 1} \pm \mathbf{1 . 6 2} \\
\text { (out of 5) }\end{array}$ & $\begin{array}{l}\text { Mean for BEO } \\
\mathbf{3 . 6 3} \pm \mathbf{1 . 0 3} \\
\text { (out of 4) }\end{array}$ \\
\hline SPECIALTY & & & \\
Internal medicine & $4.43 \pm 1.29$ & $4.67 \pm 0.73$ & $4.0 \pm 0.0$ \\
Surgery & $4.28 \pm 1.79$ & $3.9 \pm 1.59$ & $3.5 \pm 1.19$ \\
Obs and Gynae & $1.25 \pm 1.26$ & $2.75 \pm 0.96$ & $3.75 \pm 5.0$ \\
Pediatrics & $5.0 \pm 0.66$ & $4.33 \pm 1.03$ & $3.83 \pm 0.41$ \\
Family medicine & $1.33 \pm 2.31$ & $1.67 \pm 2.89$ & $1.33 \pm 2.31$ \\
House officers & $4.05 \pm 1.91$ & $3.57 \pm 1.94$ & $3.67 \pm 0.97$ \\
Others & $3.91 \pm 1.97$ & $3.64 \pm 1.92$ & $3.68 \pm 0.95$ \\
$p^{*}$ & 0.021 & 0.031 & 0.033 \\
\hline
\end{tabular}

*Kruskal-Wallis test.

The participants' ability to identify and correctly score all the specific categories of each of the three clinical variables of the current 15-item GCS was inversely related to the length/complexity of the respective variable: performance was the best for the 


\begin{tabular}{|c|c|c|c|c|c|}
\hline \multicolumn{6}{|c|}{ The Glasgow Coma Scale } \\
\hline \multicolumn{2}{|c|}{ Eye opening } & \multirow[t]{2}{*}{ Verbal Response } & \multicolumn{3}{|c|}{ Motor Response } \\
\hline & & & & Obeys command & 6 \\
\hline & & Orientated & 5 & Localising pain & 5 \\
\hline Spontaneous & 4 & Confused speech & 4 & Flexion withdrawal & 4 \\
\hline To command & 3 & Inappropriate words & 3 & Abnormal flexion (decorticate) & 3 \\
\hline To pain & 2 & Incomprehensible sounds & 2 & Extension response (decerebrate) & 2 \\
\hline None & 1 & None & 1 & None & 1 \\
\hline
\end{tabular}

FIGURE 2 |The 15-item Glasgow Coma Scale and the scoring of the clinical variables.

4-item BEO part of the scale and worst for the 6-item BMR component.

One immediately obvious limitation of this study is that it is only a single-institution questionnaire-based survey. It is also a sampling of convenience of practising physicians. Thus, it is not clear whether our findings are a picture of the general state of physicians' knowledge of the GCS in the rest of Nigeria or even in other similar regions of the world. However, our institution, the University College Hospital, Ibadan, is a flagship institute for undergraduate and postgraduate medical education in Nigeria, especially for neuroscience education in Nigeria and, arguably, in the whole of the West African subcontinent. One other apparent drawback of our work is the fact that participant "recruitment" process may partly explain the under-representation of certain cadres of physicians, especially the consultant staff, in the survey and bias in our findings. However, to the extent that the participants were not preselected in anyway, it is hoped that the findings can be expected, at least, to offer insights that are representative for the study population.

Our observation that the average physician's working knowledge of a universal clinical scale as the GCS is inadequate also raises the question as to whether the GCS might still be too "complex" and proficiency should not be assumed after all (McNarry and Goldhill, 2004; Riechers et al., 2005).

The GCS was actually developed by workers in brain trauma in Glasgow, but as it was found to be so easy to learn and simple in its application that it became a universal scale for quantifying depressed consciousness from any and all causes and, with some slight modifications, in all age groups (Jennett et al., 1976; Heard and Bebarta, 2004; Iacono and Lyons, 2005; Schefold et al., 2009; Zuercher et al., 2009; Kornbluth and Bhardwaj, 2011). The original paper where the scale was first described has since become one of the few all-time "classics" of medical literature garnering at the last count more than 5000 citations in the world literature, and still counting (Sternbach, 2000; Peters, 2010). It was after the GCS was adopted for use that the complex and often obfuscating business of quantifying states of altered consciousness became so greatly "simplified."

The GCS as described ab initio in 1974 was actually a 14-item scale (Teasdale and Jennett, 1974). A sixth motor point ("withdrawal from painful stimuli") was only added 2 years later such that the GCS then became mathematically skewed (and over weighted?) in favor of the motor response component (Jennett et al., 1976; Teasdale and Jennett, 1976; Bhatty and Kapoor, 1993; Zuercher et al., 2009). Yet if the observations by some workers that this motor component of the GCS might actually be the most objective and prognostically relevant part of the scale, then perhaps it's over weighting is just as well (Chesnut, 1997; Van de Voorde et al., 2008; Zuercher et al., 2009).

After the initial euphoria which greeted the introduction of the GCS began to ebb, then it became obvious that this simple scale might actually be unwieldy for the average practising physician. While it served its purpose and was easily learned, it did not appear as easily retained for work-a-day use (Rowley and Fielding, 1991; McNarry and Goldhill, 2004; Van de Voorde et al., 2008). A flurry of competing scales were then suggested as an attempt to correct the perceived deficiencies of the GCS. One is the Reaction Level Scale-85 (the RLS85) which even though was touted to be more discriminatory and reliable than the GCS is probably only regularly used in its country of origin, Sweden (Starmark et al., 1988; Tesseris et al., 1991; Sternbach, 2000; Kornbluth and Bhardwaj, 2011). Another is the Full Outline of UnResponsiveness scale (FOUR) score which is meant to address the GCS' inability to assess brain stem reflexes, and, also verbal response in intubated 
patients. (Wijdicks et al., 2005; Eken et al., 2009) Others include the Edinburgh-2 Coma Scale (the E2CS), (Sugiura et al., 1983; Tesseris et al., 1991) and two ultra-simple four-item-only scales; the alert, confused, drowsy, and unresponsive (ACDU) scale, and the other the Alert, responsive to Verbal stimuli, responsive to Painful stimuli, and Unresponsive (AVPU) scale of the American Trauma Life Support program (McNarry and Goldhill, 2004; Gill et al., 2007).

Currently none of these "better" scales has been able to dislodge the GCS from its entrenched status, "global" acceptance, but the continuing concern remains that the GCS, simple though it may appear to be, is still too complex and needs to be further simplified or intermittently reinforced (McNarry and Goldhill, 2004; Gill et al., 2005; Iacono and Lyons, 2005; Peters, 2010). It appears from our study that the six-item motor component of the GCS is the main culprit of this perceived complexity in an otherwise simple scale (Heim et al., 2009). The next is the five-item verbal response component (Gill et al., 2007). Perhaps what is needed is further modification of the GCS with fewer components for the clinical variables; say four items each (as for the $\mathrm{BEO}$ ) or even just three components in all for each of the three clinical variables (Gill et al., 2007).

Our report may not be the first of such pleas for a simpler GCS (Riechers et al., 2005; Peters, 2010). In point of fact, some emergency room physician experts in a Level 1 trauma unit in Loma Linda, CA, USA, have made this the clarion call of their

\section{REFERENCES}

Bhatty, G. B., and Kapoor, N. (1993). The Glasgow Coma Scale: a mathematical critique. Acta Neurochir. (Wien) 120, 132-135.

Chesnut, R. M. (1997). Appropriate use of the Glasgow Coma Scale in intubated patients: a linear regression prediction of the Glasgow verbal score from the Glasgow eye and motor scores. J. Trauma. 42, 345 .

Eken, C., Kartal, M., Bacanli, A., and Eray, O. (2009). Comparison of the Full Outline of Unresponsiveness Score Coma Scale and the Glasgow Coma Scale in an emergency setting population. Eur. J. Emerg. Med. 16, 29-36.

Gill, M., Martens, K., Lynch, E. L., Salih, A., and Green, S. M. (2007). Interrater reliability of 3 simplified neurologic scales applied to adults presenting to the emergency department with altered levels of consciousness. Ann. Emerg. Med. 49, 403-407, e401.

Gill, M., Windemuth, R., Steele, R., and Green, S. M. (2005). A comparison of the Glasgow Coma Scale score to simplified alternative scores for the prediction of traumatic brain injury outcomes. Ann. Emerg. Med. $45,37-42$.

Gill, M. R., Reiley, D. G., and Green, S. M. (2004). Interrater reliability of

recent academic effort. These workers are actually championing a three-item-only motor score, so called Simple Motor Score, as a stand-alone replacement for the composite GCS for the typical work-a-day emergency room patient care (Gill et al., 2004, 2005, 2007).

The ultimate question of course is how well a simplified GCS can hold its own in doing the job of its ancestor: durably passing the test of quantifying states of depressed consciousness objectively, precisely, reproducibly, and with great reliability and inter-observer compliance.

\section{CONCLUSION}

It is apparent from this anonymous questionnaire-based survey that the physicians' working knowledge of the GCS in a Nigerian university hospital is generally poor. This is however a single, one-time survey. It may be that larger, more inclusive multi-institutional studies would throw different insights on the issue. For now, the most detailed variable of the GCS, the motor score, presented the participants with the most difficult challenge of correctly scoring its six-item components. The GCS as it is may still be too complex and perhaps calls for further simplification. It is however not clear whether further simplification of the GCS will do an adequate job of quantifying the degree of altered states of consciousness as the current scale.

Scale. Pediatr. Crit. Care Med. 11, 423-424.

Riechers, R. G. II, Ramage, A., Brown, W., Kalehua, A., Rhee, P., Ecklund, J. M., and Ling, G. S. (2005). Physician knowledge of the Glasgow Coma Scale. J. Neurotrauma 22, 1327-1334.

Rowley, G., and Fielding, K. (1991). Reliability and accuracy of the Glasgow Coma Scale with experienced and inexperienced users. Lancet 337, 535-538.

Schefold, J. C., Storm, C., Kruger, A. Ploner, C. J., and Hasper, D. (2009). The Glasgow Coma Score is a predictor of good outcome in cardiac arrest patients treated with therapeutic hypothermia. Resuscitation 80, 658-661.

Starmark, J. E., Stalhammar, D., and Holmgren, E. (1988). The Reaction Level Scale (RLS85). Manual and guidelines. Acta Neurochir. (Wien) 91, 12-20.

Sternbach, G. L. (2000). The Glasgow Coma Scale. J. Emerg. Med. 19, 67-71.

Sugiura, K., Muraoka, K., Chishiki, T., and Baba, M. (1983). The Edinburgh-2 Coma Scale: a new scale for assessing impaired consciousness. Neurosurgery 12, 411-415.

Teasdale, G., and Jennett, B. (1974). Assessment of coma and impaired consciousness. A practical scale. Lancet 2, 81-84.

Teasdale, G., and Jennett, B. (1976). Assessment and prognosis of coma after head injury. Acta Neurochir. (Wien) 34, 45-55.

Teasdale, G., and Jennett, B. (1978). Assessment of coma and severity of brain damage. Anesthesiology 49, 225-226.

Teasdale, G., Knill-Jones, R., and Van Der Sande, J. (1978). Observer variability in assessing impaired consciousness and coma. J. Neurol. Neurosurg. Psychiatr. 41, 603-610.

Tesseris, J., Pantazidis, N., Routsi, C., and Fragoulakis, D. (1991). A Comparative Study of the Reaction Level Scale (RLS 85) with Glasgow Coma Scale (GCS) and Edinburgh-2 Coma Scale (modified) (EzCS(M)). Acta Neurochir. (Wien) 110, 65-76.

Van de Voorde, P., Sabbe, M., Rizopoulos, D., Tsonaka, R., De Jaeger, A., Lesaffre, E., and Peters, M. (2008). Assessing the level of consciousness in children: a plea for the Glasgow Coma Motor subscore. Resuscitation 76, 175-179.

Wijdicks, E. F., Bamlet, W. R., Maramattom, B. V., Manno, E. M., and Mcclelland, R. L. (2005). Validation of a new coma scale: the FOUR score. Ann. Neurol. 58, 585-593.

Zuercher, M., Ummenhofer, W., Baltussen, A., and Walder, B. (2009). 
The use of Glasgow Coma Scale in injury assessment: a critical review. Brain Inj. 23, 371-384.

Conflict of Interest Statement: The authors declare that the research was conducted in the absence of any commercial or financial relationships that could be construed as a potential conflict of interest.

Received: 16 January 2012; paper pending published: 30 January 2012; accepted: 16 February 2012; published online: 09 March 2012.

Citation: Adeleye AO, Owolab MO, Rabiu TB and Orimadegun
AE (2012) Physicians' knowledge of the Glasgow Coma Scale in a Nigerian university hospital: is the simple GCS still too complex? Front. Neur. 3:28. doi:10.3389/fneur.2012. 00028

This article was submitted to Frontiers in Neurology Education, a specialty of Frontiers in Neurology.
Copyright (C) 2012 Adeleye, Owolabi, Rabiu and Orimadegun. This is an openaccess article distributed under the terms of the Creative Commons Attribution Non Commercial License, which permits non-commercial use, distribution and reproduction in other forums, provided the original authors and source are credited. 


\section{APPENDIX \\ PHYSICIAN KNOWLEDGE OF THE GCS \\ Clinical tool physician survey}

You are being asked to participate in a survey of physicians' familiarity with a commonly used clinical tool. You have been selected to participate in this survey because of the likelihood that many of your daily contacts with patients may call for the use of this tool; it is also presumed that you must have received many didactic teachings in the use of this tool in the course of both your medical school and postgraduate education. Your participation is voluntary and neither your name nor other personal identifiers will be needed for data analysis. Your answers will remain anonymous. If you choose to continue please follow the instructions below. Please circle the correct options or fill out the answers to the best of your ability. No reference materials, please.

1. Current level of training

(1) House/Medical Officer, (2) Resident, (3) Consultant, (4) Others (Please specify)

2. Primary Specialty: (if any) Subspecialty

3. Number of years out of medical school

4. Duration of medical practice

5. Any additional formal medical training? 1. Yes 2. No

6. If yes, please specify (1) Residency training (2) Postgraduate degrees (3) Others

7. Duration of additional formal medical training

8. Last time actively involved in Accident and Emergency room care of patients $(1)<1$ weeks $(2)<2$ weeks $(3)<1$ months $(4)$ $<3$ months (5) $>3$ months

9. Or the last time actively involved in any other Emergency Medicine care outside the Accident and Emergency (A and E) room

10. Duration of active A and E coverage that you have had in your clinical practice

11. How often do you come into contact with unconscious patients?

1. Very frequently 2 . often 3 . Occasionally 4 . Rarely

12. How important do you think the GCS is in assessing unconscious patients?

1. Very important 2. Somewhat important 3. Not so important 4 . Not sure

1. You are being asked about your recall of the commonly used GCS. Please tell us what GCS stands for.

GCS _ G__ C___ S _ _ _ _

2. Are we correct in assuming that you must have received didactic teachings/lectures on the meaning and the use of the GCS some times in your medical training?

(1) Yes 2 (2) No

3. The GCS relies on three clinical variables. Please name them and assign the appropriate clinical response for each numeric score in that category. Six potential scores are available for each clinical variable, however you will recall that not all categories receive six points. Please mark N/A (i.e., not applicable) where appropriate. Score clinical variable \#1

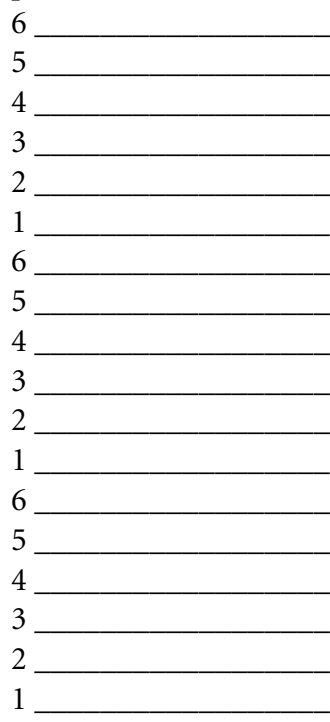

Clinical variable \#2

Clinical variable \#3 